\title{
Présentation des deux articles qui suivent
}

\section{(2) OpenEdition}

1 Journals

Édition électronique

URL : http://journals.openedition.org/trema/2887

DOI : $10.4000 /$ trema.2887

ISSN : 2107-0997

\section{Éditeur}

Faculté d'Éducation de l'université de Montpellier

\section{Édition imprimée}

Date de publication : 1 janvier 2003

Pagination : 20

ISSN : 1167-315X

\section{Référence électronique}

«Présentation des deux articles qui suivent », Tréma [En ligne], 20-21 | 2003, mis en ligne le 11 janvier 2013, consulté le 21 avril 2019. URL : http://journals.openedition.org/trema/2887 ; DOI : 10.4000/ trema.2887

Ce document a été généré automatiquement le 21 avril 2019

Trema 


\section{Présentation des deux articles qui suivent}

1 Nous présentons ici deux articles, fruits du travail de recherche, sur le site de Perpignan, mené par l'équipe LIRDEF-ALFA, de l'IUFM de Montpellier, dans le cadre de recherches sur l'écriture en formation. Nous avons mis en place en 2001-2002 pour les quatre groupes de stagiaires PE2, un portfolio, après une expérimentation préalable, pendant deux ans (1998-2000) à l'initiative de J.C. Chabanne et D. Bucheton pour deux groupes de stagiaires. Le portfolio comprend plusieurs éléments dont un journal de bord, tous rédigés à l'occasion des divers stages. C'est un instrument d'évaluation autant formatif que sommatif.

2 Le premier article, Le journal de bord en formation : une parole de travail, co-rédigé par Dominique Bucheton et Alain Decron, avec la collaboration de J.C. Chabanne, Jacky Caillier et Marc Parayre, étudie la manière dont des postures d'enseignement diverses se mettent en place en cours d'année, et la façon dont l'écriture sur la pratique peut étayer les démarches réflexives des stagiaires. L'article propose ainsi des outils d'observation du développement des compétences et de l'identité professionnelles.

3 Le deuxième article, Du portfolio au dossier professionnel, rédigé par D. Bucheton, poursuit la réflexion sur le rôle de l'écriture en formation, plus particulièrement sur le rôle du portfolio. Mais cette fois dans un cadre élargi puisqu'il prend en compte une expérimentation sur quatre groupes de "formation générale et commune", ceux de C. Asdhi, C. Dupuy, D. Bucheton et B. Bois, pendant l'année 2001-2002. Ce deuxième article se veut une contribution à la réflexion commune sur la nécessité de mettre en place de nouveau dispositifs de formation et d'évaluation des stagiaires. 